\section{Psychosexual bodywork: should we refer our patients, and if so why?}

A recent Journal article ${ }^{1}$ had the same effect on these readers as the mention of bodywork did at the workshop on vaginismus and sexual pain: a palpable shiver! However we recognise these feelings for what they are: discomfort, ignorance and fear. A casual glance at the article could lead to a misinterpretation that bodywork is a recognised part of psychosexual medicine. On deeper reading, it becomes clearer that this form of therapy is practised by only a small group of non-medical therapists who traditionally do not examine patients/clients. The Institute of Psychosexual Medicine (IPM) trains doctors in psychosexual medicine and fundamental to this training is the genital examination. During the examination, the doctor observes the reaction and emotions expressed by the patient as well as the feelings evoked in the doctor. In that short moment of vulnerability, a further shared understanding of the patient's problem can evolve. In this way we acknowledge the discomfort and fear that are exposed during examination, often reflecting underlying psychosexual issues. It is within this framework that the psychosexual consultation is therapeutic in a similar manner to the patients/clients discussed in this article: post-surgery, postpartum, in abusive or demanding relationships.

However, the concept of taking that examination further with direct sexual stimulation, even with the consent of the patient, goes against many principles of medicine, and contravenes all the rules on patient-doctor interactions from the General Medical Council. The therapists involved in bodywork are taking the role of sexual surrogates. Although this may be appropriate for individual patients, it is likely to often leave both the therapist and patient/ client extremely vulnerable irrespective of charters determined before consultation and agreement of 'safe' words to extricate a patient who feels distressed. 'Experiential learning' in the context of a relationship developed by re-establishing the connection between mind and body in the consultation room underpins the work of the 'secret army $^{2}$ of psychosexual doctors working around the UK.

The IPM would like to stress that bodywork is not, and will never be, part of the therapy offered by its members.

John Ewan, MB BS, DFSRH

Associate Specialist, Sandyford, Glasgow, UK and Member of the Institute of Psychosexual Medicine

Claudine Domoney, MB BChir, MRCOG

Consultant Obstetrician and Gynaecologist, Chelsea and Westminster Hospital, London, UK and Chair of the Institute of Psychosexual Medicine

Competing interests None.

J Fam Plann Reprod Health Care 2012;38:141.

doi:10.1136/fprhc-2011-100264

\section{References}

1 Quilliam S. Psychosexual bodywork: should we refer our patients, and if so why? J Fam Plann Reprod Health Care 2011;37:241-243.

2 Domoney C, Elliman A. Training skills in psychosexual medicine [Letter]. J Fam Plann Reprod Health Care 2011;37:61-62; author reply 62. 